\title{
Access Denied: Memory and Resistance in the Contemporary Ghost Film
}

To relive the past: that insistent impossibility of psychoanalysis and film. These forms of retelling invite, even demand, a distracted vision that flickers back and forth, scene by scene, repeating a past that is a present out of time. This essay examines the meditation on loss, frozen time and uncanny aftermaths in the contemporary ghost films What Lies Beneath (dir. Robert Zemeckis, 2000) and The Others (dir. Alejandro Amenábar, 2001) in light of debates surrounding trauma, therapy and recovered memory over the last two decades. In these confessional cinematic tales, there is nothing to escape, no 'guilt' to confess, yet a traumatic event structures each film, and the very act of resistance to remembering irresistibly draws its 'survivor' back to that haunting moment. This model of restlessness, of unfinished business, is not readily assimilable to standard notions of repression, and stands as a counterpoint to the imperatives within contemporary therapy culture to reveal, recover and bring a closure to the traumatic past. What Lies Beneath and The Others refuse to offer such closure.

The protagonists in both films are lodged at once inside and outside trauma; in The Others, the dead mother and children impossibly live on after their trauma, and in What Lies Beneath, the traumatic forgetting of others (the husband's, the murdered lover) is performed. As such, their traumatic remembering is placeless and timeless. According to Ulrich Baer, in trauma there is a 'twofold structural disjunction between an experience and its integration into narrative memory’; such experiences are 'located somewhere outside memory yet within the psyche’ (Baer 10). Thus the trauma of the other cannot be fully determined or represented. Both films at once deny and grant a hearing to the returning dead, and their central protagonists live in the aftermath of some unspoken, unspeakable event. At one level, the 
unspeakable in The Others is the history of collaboration in Jersey during the Nazi occupation. According to Grace, the Germans kept cutting off the electricity supply, but in five years never managed to enter the house. She resists this unassimilable external force just as she eventually repels the current intruders, the Marlishes. Yet, when Charles 'returns' from the front, he is asked why he joined the war effort when 'we all surrendered', and became involved in a war that had no relevance to his family. What Lies Beneath is marked by two decades of judicial and legislative debates over the legitimacy of recovered memory and Post-Traumatic Stress Disorder (PTSD), which are debates about the very nature of the unsayable.

The films draw on a classic Gothic repertoire - isolated houses, enclosed or suffocating spaces, obscure depths, the returning dead, various forms of crypt, and the disturbance of the domestic sphere - and the countervailing demands to resist and access a past is figured in terms of rooms that are revisited, re-locked and re-opened, actions obsessively performed, mists that clear and envelop. Yet these are narratives that do not readily give up their secrets. Visually, each narrative deploys a limited colour palette, as if to suggest an environment voided of affect, or one that permits little illumination. In What Lies Beneath, truth is sought in reflective surfaces - mirrors, water - but 'the truth' cannot be glimpsed inside oneself: it is encountered only in another's unsettled account, and that encounter imposes obligation and responsibility on the one who witnesses. The Others also involves responsibility, and the recognition of wounds that do not heal: access to reparation and closure is denied. Despite appearances, the narrative's rituals of barring and enclosure do not shut up, or out, the truth of one's guilt, do not conceal or cover over a traumatic breach which the light of revelation will assuage. The light that eventually floods into the sombre interior does not provide restitution, but rather enables the subjects of trauma to live with 
(which is not the same as being enmeshed within) that trauma. As such, trauma underwrites the possibility of survival in The Others. In What Lies Beneath, the undertaking - the proper laying to rest - of the murdered girl is also an overtaking; trauma overtakes and underwrites, in the sense of guaranteeing a certain future, the present. Both films therefore conduct a laying to rest that comes after a reawakening.

\section{Distracted vision}

The unsettlement of these ghost films can be viewed in relation to Freud's anecdote about involuntary repetition in 'The Uncanny', in which he recalls his 'voyages of discovery' in a provincial Italian town, when he kept returning as if by design to a red-light district he was desperate (we presume) to escape:

As I was walking, one hot summer afternoon, through the deserted streets of a provincial town in Italy which was unknown to me, I found myself in a quarter of whose character I could not long remain in doubt. Nothing but painted women were to be seen at the windows of the small houses, and I hastened to leave the narrow street at the next turning. But after having wandered about for a time without inquiring my way, I suddenly found myself back in the same street, where my presence was now beginning to excite attention. I hurried away once more, only to arrive by another détour at the same place yet a third time. Now, however, a feeling overcame me which I can only describe as uncanny, and I was glad enough to find myself back at the piazza I had left only a short while before, without any further voyages of 
discovery. (Freud PFL 14 359)

In this picaresque adventure, Freud is seemingly unable to escape a labyrinth of temptation and anxiety. His account is confessional in character: he wants to tell his story, but is unsure about what the story tells. Freud succumbs to an uncanny feeling only when emerging from the apparently infinitely recesses of his enigmatic, disorientating experience, only when returning to the proper light of day. A sense of the uncanny emerges belatedly, and there is no attempt to account for the unconscious determinants that may have guided the sunstruck protagonist's repetitive steps. One can argue that Freud's anecdotal cataloguing of uncanny experiences such as this dwells on the aftermath of disturbing or unsettling events, rather than the pursuit of the uncanny moment back to its origin. The uncanny is treated as an event without origin, a remainder or survival. The feelings of helplessness and drift these distracted perambulations inspire locate the uncanny as a spatial and temporal resting-point which never allows us to advance, and yet which never allows us to stand comfortably still. As he wanders with increasing discomfort under the Italian sun, Freud's movements constitute a form of restance, a word that suggests re-instance, resistance and drift. ${ }^{1}$

In recounting the story, Freud occupies the roles of witness and of unwilling, unwitting participant. As participant, he cannot stop returning, and as witness he cannot ever return: in each case, however, the event 'lives on' and underwrites the present. This concern with involuntary repetition is shaped by his work on traumatic and war neuroses in Beyond the Pleasure Principle, published one year after 'The Uncanny'. Freud observes that patients suffering from traumatic neurosis are not 'occupied in their waking lives with memories of their accident' and may be more concerned with 'not thinking of it'. Yet their dreams 'have the characteristic of repeatedly bringing the patient back into the situation of his accident, a 
situation from which he wakes up in another fright' (Freud, Beyond the Pleasure Principle, 282). Traumatic neurosis is thus puzzlingly resistant to the concept of wishfulfillment, since the traumatic event returns against the subject's wishes. In addition, traumatic neurosis, or what now can be defined as post-traumatic stress disorder, cannot be defined in relation to an originary event or its subsequent distortion by the unconscious mind. Those who live with trauma live with a past they cannot capture or dispense with. As Caruth comments, the pathology of trauma consists 'solely in the structure of its experience or reception: the event is not assimilated or experienced fully at the time, but only belatedly, in its repeated possession of the one who experiences it. To be traumatized is precisely to be possessed by an image or event' (Caruth, Trauma: Explorations in Memory, 4-5).

Freud illustrates such possession by the image or the event by citing Tasso's tale of Tancred and Clorinda. Tancred, having unwittingly killed his beloved Clorinda in a duel, travels through a magic forest which terrifies his fellow Crusaders. When he slashes a tree with his sword, blood pours from the cut and Clorinda, whose soul has been imprisoned in the tree, is heard to lament that her lover has yet again inflicted a wound upon her. Caruth finds this example striking not just for 'the unconscious act of infliction of the injury and its inadvertent and unwished-for repetition, but the moving and sorrowful voice that cries out, a voice that is paradoxically released through the wound' (Caruth, Unclaimed Experience). What we hear is 'the enigma of the otherness of a human voice that cries out from the wound' (3). In the distracted visions of The Others and What Lies Beneath, the uncanny 'possession' of trauma transmits itself between victim and witness, and acts of repetition bear witness to this enigmatic voice. In The Others, the obsessive concern with sealing off, confining and obscuring re-enacts Grace’s smothering of her children. Every time she shuts out light, or 
shuts in her children to protect them, she repeats the traumatic moment. Similarly, in What Lies Beneath, every time that Claire bathes or plunges into water, and then surfaces without knowing what lies beneath, she repeats the violence and deception that submerges the 'other' betrayed woman. It is only when Claire returns from the depths, having enabled the unquiet spirit to emerge, that she can bear witness to trauma.

\section{Trauma and the Talking Ear}

Since the late 1980s, ideas surrounding trauma, recovered memory, confession and closure have spilled out beyond clinics and consulting rooms to courts, legislative debating chambers and primetime television studios. In the US, medicine, trauma, law and politics have been closely interwoven since the Vietnam War. As Paul Antze and Michael Lambek observed a decade ago: 'Increasingly, memory worth talking about - worth remembering - is memory of trauma' (Antze and Lambek xii), and Richard McNally remarks that by the end of the 1980s, the 'reluctance to disclose' of abuse survivors became 'inability to remember' (McNally 5). A dual conviction drove therapy culture at this time: a conviction that there was a story that was not being told, and a conviction that therapy could uncover what could not be told. Peter Brooks argues that without confessional discourse, the modern notion of autonomous self would collapse: the talking cure 'has evolved into a generalized belief in the catharsis of confession, of the value of telling all, in public' (Brooks 140). Yet does this confessional discourse reveal psychic truth or referential truth? It may be difficult to distinguish between these forms of truth, but in a court of law examining a case of child abuse such distinctions are crucial. As Freud acknowledges, however, analysis differs from confession; while both analyst and priest must elicit a 'confessional mode of discourse’ (Brooks 116-7), analysis suspects 
confession and must supplement it. (It is of course striking that Freud-as-analyst cannot supplement his account of that uncanny experience in the provincial Italian town.) Confession is interested, marked by resistance and transference, and therefore resistance needs to be broken down, obstacles removed and a symptomatic narrative deciphered and reordered for therapeutic purposes. The work of analysis is thus performative in a way that confession cannot be. The analyst must simultaneously take up the place of the confessant, and act upon the secret, not just receive it passively. The true self that confession lays bare may not closely conform to the external world, and 'the confessional talk of psychoanalysis suggests that confession can be less a definition of the truth than a search for it, a posing of the question: who am I?’ (Brooks 141).

It is the non-verifiable status of confession that has provoked so much controversy in the last two decades, leading in one instance to the establishment of the False Memory Syndrome Foundation in US in 1992 to fight an alleged epidemic of compelling but false memories of abuse. Psychoanalysis is of course centrally implicated in what Todd Dufresne has termed the plague of contemporary therapy culture (Dufresne viii). In the Freud Wars, critics levelled their sights in two ways: Freud was accused either of denying the reality of childhood abuse when he abandoned seduction theory, or of suggesting and producing the false memory of trauma in developing his theory of fantasy. In this account, Freud inaugurates psychoanalysis by falsifying his findings, and his therapeutic technique in turn produces further, damaging falsifications in the consulting room. As Dufresne argues, 'the myth of the unconscious is the direct result of a paranoid discourse bent on proving its own assumptions; a discourse, moreover, that not only provides a symptom language, but makes people sick because of it'. The theory of the unconscious encourages both analyst and patient to dredge 
deep until they find ‘a dual consciousness that doesn’t exist except as an outmoded theory of spirit possession’ (Dufresne 23). Dufresne contends that a dose of repression, far from preventing a cure, actually aids recovery from trauma (24). So much, as he says, for psychoanalysis as a therapeutic response to a traumatic past: survivors of abuse should actively resist the talking cure and soldier on.

Yet other forms of clinical diagnosis and classification have proved equally problematic. Cathy Caruth has observed how the recognition of PTSD in 1980 has complicated the understanding of pathology (Caruth, Trauma: Explorations in Memory 3). The very symptomatology and uncanny repetitions of this condition disrupt conventional ideas of diagnosis and cure. If trauma has become an all-inclusive phenomenon, it is so because it 'brings us to the limits of our understanding; if psychoanalysis, psychiatry, sociology, and even literature are beginning to hear each other anew in the study of trauma, it is because they are listening through the radical disruption and gaps of traumatic experience' (4). Trauma is presented here in terms of the difficulty and possibility of listening. Dori Laub has cast the response to trauma precisely in terms of listening and witnessing. For Laub, ‘the victim’s narrative - the very process of bearing witness to massive trauma - begins with someone who testifies to an absence' (Felman and Laub 57). This testimony to trauma includes the hearer, who becomes the blank screen on which the event is inscribed for the first time. The listener is a witness to witness in both senses: she hears the one who experiences trauma, thus witnessing to that trauma, and also listens, or witnesses, to the act of witness. The listener must listen to and hear silence, speaking mutely in silence and in speech (Felman and Laub 58). The act of witnessing also involves an uncanny repetition of events that duplicate or rehearse (in the 
sense that the past event is yet to come, or to happen in memory) the 'original' traumatic event.

To listen to the traumatic absences of film is to become a screen onto which its silent cuts can be projected. Film plays with revenants, eerie doubles and the sudden intrusion of past into present; in his study of the double, Otto Rank found early cinematography unique in 'visibly portraying psychological events' (Rank 7). Nicholas Royle remarks that film is 'an affair of the ear, of the talking ear' (Royle 80), and can perhaps allow us to bear witness audibly and visibly to the traumatic wound or event, to make it 'live' again. As Joshua Hirsch has emphasised, through 'the indexical recording of images and sounds' cinema can bear witness to 'external' trauma in imitative fashion but, since it involves us so fundamentally in the imaginary, it also witnesses to psychological reality (Hirsch 6-7). More problematically, it permits vicarious trauma, which can erase the different positions of victim, eyewitness and spectator. In an interesting twist, both films under discussion make available intratextually all three of these positions for its central protagonists. The central protagonists in The Others and What Lies Beneath are listeners and witness-victims, and the latter part of the discussion will explore Laub’s sense of silent but participatory listening in the two films. But before that affair of the ear I want to return to Freud's understanding of the traumatic event.

\section{When We Dead Awaken}

As Cathy Caruth argues: 'Traumatic experience, beyond the psychological dimension of suffering, suggests a certain paradox: that the most direct seeing of a violent event may occur as an absolute inability to know it, that immediacy, paradoxically, may take the form of 
belatedness' (Caruth, 'Traumatic Awakenings' 89). This paradox is graphically illustrated for her in Freud's account of the 'model' dream of 'the Burning Child':

A father had been watching beside his child's sick-bed for days and nights on end. After the child had died, he went into the next room to lie down, but left the door open so that he could see from his bedroom into the room in which his child's body was laid out, with tall candles standing round it. An old man had been engaged to keep watch over it, and sat beside the body murmuring prayers. After a few hours' sleep, the father had a dream that his child was standing beside his bed, caught him by the arm and whispered to him reproachfully: 'Father, don't you see I'm burning? He woke up, noticed a bright glare of light from the next room, hurried into it and found the old watchman had dropped off to sleep and that the wrappings and one of the arms of his beloved child's dead body had been burned by a lighted candle that had fallen on them. (Freud, The Interpretation of Dreams 652)

This dream reaches Freud through a series of acts of witnessing or listening: '[i]t was told to me by a woman patient who had herself heard it in a lecture on dreams; its actual source is still unknown to me' (652). This is a dream without origin, both within the frame of the dream and in its transmission recalls. The dream's uncanny, 'sourceless' repetition recalls Freud's voyages in the Italian red-light area: the father does not wish to relive a moment that was missed in its first instance, yet he is compelled to return, even if that return is at once resisted and impossible. The father's dream-wish to keep the child alive is bound up with a more enigmatic wish to stay asleep, an instance of a fundamental desire of consciousness 'not to 
wake up'. The dream-wish is for a suspension of consciousness: a wish that consciousness be subject to a delay, and a wish that death will not catch up with life in the fantasy.

As Freud summarises, the dream 'was preferred to a waking reflection because it was able to show the child as once more alive' (653) Lacan, however, notes that the wish to sleep is countermanded not just by external forces - the light of the fire - but is demanded from within the dream. It is the dream that wakes the sleeper, rather than prolonging itself. For Lacan, the dream is a function of awakening. The force of the trauma is not death alone, but the father's failure to witness the child's death:

Is not the dream essentially, one might say, an act of homage to the missed reality - the reality that can no longer produce itself except by repeating endlessly in some never attained awakening? ... Only a rite, an endlessly repeated act, can commemorate this not very memorable encounter - for no one can say what the death of a child is, except the father qua father, that is to say, no conscious being. (Lacan 58, 59)

The traumatic event is 'knotted, unassimilated ... inaccessible to reflection, contemplation, or undoing' (Ragland 82-3). The father can only contemplate what the aftermath of the child's death means: the experience of trauma is the experience of what comes after. Awakening is thus the site of trauma, of the necessity and impossibility of responding to another's death. The bonding of the father with the child is tied up with necessity and impossibility of confronting death. This bond is linked to missing the child's death, a temporal contradiction that repeats and misses the child's presence. It marks out an uncanny suspension of life and death, a repetition or enigmatic call that issues from no visible, discernible person or place. As 
Caruth observes, the father's survival can be understood as 'a mode of existence determined by the impossible structure of the response’ (Caruth, ‘Traumatic Awakenings' 97). To live on after the missed encounter with death is our anguish and our responsibility. Death is always too soon, never at its proper time, never proper to us. The father's story of survival is ineluctably bound up with the child's words, and thus the story of the survivor is no longer the father's own, but a story that responds to the dead child’s story. As Caruth, via Lacan, stresses, this is ‘a story of urgent responsibility’ and of an ethical relation to the real (98).

The father's failure to witness, to respond to the child's call, is a failure to see both inside and outside: he does not see in time the negligence that allows the bed to catch fire, and did not see the child at the point of death. The child, however, does not call the father back to remain in his dream that will suspend the reality of death. Caruth emphasises that he tells his father to awaken, to testify: 'it is precisely the dead child, the child in its irreducible inaccessibility and otherness, who says to the father: wake up, leave me, survive, survive to tell the story of my burning' (100-1). The father thus becomes one who can say 'what the death of a child is': this response is not about knowing, but the performance of speaking this carries with it the child's otherness.

Is awakening, then, in its inability to see, a true reception of an address? The address can be overheard as 'See me/ I can’t see/ That is what you must tell you have seen.' Awakening is thus not an understanding but a transmission. Caruth argues that awakening is an act that repeats a departure and a difference: it is the departure of the survivor at the behest of the dead, and it is the intolerable difference between psychical afterlife and physical loss, or the difference between burning within and burning without (102). Freud and Lacan’s dream analyses are uncannily repeated in their own private losses: Freud's text is soon followed by 
the death of his daughter Sophie; and Lacan's reading is marked by the death of his daughter Caroline a few years after he delivered his seminar on the dream of the burning child. We discern here the structure of testimony: first, there is delayed testimony in the dream, then delayed testimony beyond the dream - testimony delayed twice over.

In keeping with this structure of delay, The Others and What Lies Beneath portray the time of the survivor, but in each case that survival is paradoxical. Both films witness to witness, and engage in the silent, implicated listening outlined by Laub. The Others is set in a wintry Jersey in 1945, and centres on Grace and her two children Nicholas and Anne. Grace’s husband, Charles, is said to be serving at the front. They inhabit a gloomy house wreathed in thick fog. It opens with Grace in voiceover saying 'Now, children, are you sitting comfortably?' and beginning to tell the story of Creation while we see a series of drawings of domestic scenes. Thus we start with an inductive narrative strongly informed by religious faith, and by the twin imperatives to testify and to listen. The ‘truth' unfolds through multiple acts of participatory listening: Grace gradually believes her children's tales of intruders, and finally learns the reality of her situation from her servants: that they are all ghosts, 'survivors' of the house's often traumatic history.

The untimely awakening to the truth is prefigured in the film's opening scenes. From the title sequence, we cut to Grace screaming in her bed, as if waking from a nightmare. Three shadowy servants - Mrs Mills, Mr Tuttle and a mute young woman, Lydia - have knocked on the door, although Grace ‘wasn’t expecting them so soon’. We first encounter the children as they emerge from behind a locked door, having just been woken. They are said to be photosensitive, highly allergic to light, which were they to be exposed to it, would quickly suffocate them. As Grace says, the only thing in the house that moves is the light, but it 
‘changes everything'. Later, when Grace and the children acknowledge that Charles has 'moved on', the curtains are removed by the new occupants, and light floods in without malign effect. The children are only photosensitive 'before' the registering of the traumatic event. The children often allude to Mummy's madness, and to an unnamed event; Anne affirms 'it did happen', while Nicholas lives in denial. Grace maintains her defences through a process of splitting, separating out the one who suffers and the one who survives. Silence is 'prized very highly' in the house; and at times, as she admits, 'this house is not an ideal home'. She does not like 'fantasies' or 'strange ideas' and repeatedly uses Biblical maxims to stress the importance of truthfulness, but she punishes Anne harshly for her truthfulness in being able to identify the 'intruders'.

Mrs Mills is constantly on the point of telling all, but must instead listen silently and hear the story. She does not respond when Grace - correctly - speculates that Lydia has become mute due to some trauma. She is a strange counterpart of the blind medium that the 'intruders', the Marlish family, have employed to contact and exorcise the domestic ghosts. When the presence of ghosts or intruders can no longer be denied, Grace accepts that 'there is something which is not at rest' in the house. Mrs Mills comments that 'we've all heard stories of "beyond", and that 'sometimes the world of the dead gets mixed up with the world of the living. When Grace asserts that 'the Lord would never allow such an aberration', Mrs Mills replies that 'there isn't always an answer for everything'. Yet revelation or discovery remains subject to delay. As Grace leaves the house to seek answers from the village priest, Mr Tuttle is seen heaping dead leaves over gravestones to obscure them: Mrs Mills remarks that there is not yet a need to 'bring this out into the open'. Grace plunges into the fog, and meets Charles as he 'returns' from the front. When she says 'They said I should give you up for dead', he 
replies that 'They say a lot of things', alluding to voices that have encouraged Grace to move on, to relinquish the past. Yet the film's unsettled account with the dead is underscored by Charles's apparent status as missing in action. The past lives as the experience of aftershock: Grace cannot fully confess her 'crime' to Charles during his brief return, even though the children have told him 'what happened'. When Grace uncovers a Victorian Book of the Dead, in which corpses are arranged fully dressed for the camera, she cannot fathom the motivation behind such uncanny still lives. Yet the pictures, which stage the uncertainty between the living and dead body that marks the uncanny, figure precisely the suspended inanimation of the house's inhabitants.

At the same moment as Anne and Nicholas uncover the gravestones of the three servants, Grace discovers their portrait in the Book of the Dead. Neither Grace nor the children can hide any longer from spectrality; in listening to the servants, they are also obliged to listen to the intruders. The Marlishes are holding a séance to make contact with the restless ghosts of the house. It is during the séance that we learn the secret: that, on learning of her husband's death at the front, Grace smothered her children and shot herself. It is all-too tempting to read this traumatic confession in terms of exposure and closure, but the process of transmission and active listening does not exorcise or lay to rest the house's ghostly inhabitants. The medium, and all those gathered around the table, 'wake up' to bear witness to the story of 'burning', the missed encounter with death. If the survivors are able to move on, it is only in the sense that the Marlishes decide to leave the house the next morning. The recovered memory enables an opening to a kind of future for Grace and the children, a way of 'moving on' even as they remain in 'our house’. Domestic normality seems to have resumed when Mrs Mills offers a cup of tea, but the household must remain caught up in the aftershock 
of trauma. They have experienced the trauma of their sudden death belatedly, and must 'live on' in a perpetual recurrence of that belatedness. As an eavesdropper on the aftermath, the listener/ spectator becomes a survivor too, obliged to listen to that 'original' moment of overwhelming pain and loss. Like the burning child, these ghosts demand an impossible response: they ask that the listener return from the missed encounter with death, and bear witness to the traumatic event that had no witness.

As in The Others, trauma is an intruder in What Lies Beneath, but this time it is another's trauma. The film involves Claire Spencer, a former classical musician who sacrificed her career for marriage to her husband Norman, a genetic scientist. Haunted by visions of a young woman, whom she eventually identifies as Madison Frank, a missing person, Claire uncovers first Norman's affair with Madison, then his murder of her. Claire is a survivor, and must bear witness to the traumatic event that she did not witness. The opening credits overlay the swirling, misty waters of a lake, before the shot dissolves into its weedstrewn depths. We then surface first in the form of a dead woman's face, which in turn blends into Claire's face in the bath. There are numerous scenes of such mirroring; in mirror-images that force a double-take, Claire glimpses Madison's ghostly form in a full bathtub, and in the lake adjacent to their house. At one point, as Claire is in the process of unravelling Charles's deception, there is an eerie scene of mimicry where Claire assumes, or is possessed by, the spirit of her dead counterpart.

Early in the narrative, we see Claire anxiously parting from her daughter who is leaving for college, a departure made more difficult by the fact that Claire is still recovering from a car accident the previous year. Her growing belief that the family home is haunted is attributed to a delayed reaction to this traumatic event. Sensing something wrong close to 
home, Claire spies on her new neighbours the Feurs, who have a passionate and violent relationship. Claire first misdiagnoses Mrs Feur's psychological distress across the garden fence, then wrongly believes that she has been killed by her husband. To exorcise the ghostly presence, she consults in turn an analyst, a book on demonology and witchcraft that proves extremely effective in conjuring Madison's spirit, and a ouija board. In a knowing allusion to the recovered memory controversy, the paraphenalia of satanic abuse is introduced to an elite New England home; Claire and Norman eventually burn a braid of the dead woman's hair to banish her from the house. Prompted by friends, and piecing together fragmentary evidence, Claire slowly 'remembers’ that she had seen Norman with Madison at his Professorial inauguration party, and had guessed their secret at the time. This explains the ghostly message in a misted bathroom mirror: 'You know'. Claire’s car-crash might thus have been a suicide attempt that she has repressed. As Madison’s past becomes more tangible, however, the extent to which it is Claire's trauma, or buried memory, that is at stake in this tale of haunting is questionable. Yet when Norman confesses to his affair, he 'counsels' Claire in such a way that another's responsibility becomes her responsibility, even as he claims to be helping to relieve her of her burden. Norman speaks: he does not listen. In a brief, quasi-therapeutic encounter, Claire claims that there is a 'presence in the house' who is 'a young blond girl', and that she has unwittingly opened the door to this ghost. Norman's response positions Claire as the victim of abuse or sexual violence: 'it's not your fault. Say it - it's not your fault'. She is at once asked to relinquish responsibility and obliged to account for her victimhood, turning her into the mirror image of the other blond woman who haunts their home. Yet this identification is not merely a passive reflection; Claire withdraws from Norman, clearly unconvinced by his reassuring tone. In this scene, Claire has moved from victim - a word that directs attention 'to 
perpetrators and to the damage they have inflicted on others' (McNally 2) - to survivor, one who emerges to listen, and breaks the dependency that victim status can perpetuate. As such, this is an active identification with Madison, who in her spectral visitations 'survives' the traumatic event.

Yet the responsibility to confess to a traumatic past - a past that is not Claire's alone cannot easily be evaded. This responsibility is emphasised by Ellen Bass and Laura Davis in The Courage to Heal: ‘If you don’t remember your abuse, you're not alone. Many women don't have memories, and some never get memories. This doesn't mean they weren't abused' (Bass and Davis 81). This injunction to remember evokes an originary traumatic trace, a moment anterior to consciousness, and is less an obligation to witness than an exhortation to take command of a shared past. This imposes on us a responsibility for and to others, but it is impelled by a diagnostic or hermeneutic zeal far removed from Laub’s silent, participatory listening. Trauma has happened: it is the predicate of the future, and only awaits its exposure. It is precisely this sense of conviction, which often led to the conviction of others, that fuelled the controversies over recovered and false memory in the early 1990s (McNally 14-15). It has also given way to the ubiqituous, often questionable and ultimately desensitising invocation of 'trauma', and its endless relaying through word and image. Under the therapeutic imperative outlined by Bass and Davis, there will be victims, abuses and secrets to find. Yet What Lies Beneath negotiates between two competing versions of witness. Claire is continually positioned as the self-policing subject obliged to acknowledge and account for her damage, and yet she increasingly assumes the role of a silent listener who opens up to the shock, the uncanny punctuation, of trauma. Claire is constantly encouraged to forget, move on and adjust, yet she refuses; she knows there is something, but it is not in her. It is the extension of 
the therapeutic imperative, and its overdetermined pursuit of abuse, that leads Claire to misconstrue her neighbours' intense marital relationship; her witnessing of apparent domestic violence initially obscures the trauma of another who did experience fatal violence. This seems to position Claire - and in turn the cinematic spectator - as a 'vicarious' witness. Hirsch discusses the way in which the witness's point of view can be transferred 'to a nonwitness through vicarious traumatization' in cinematic and documentary images, and also in the analytic encounter (Hirsch 22). In What Lies Beneath, this relay of vicarious traumatization includes Claire, Norman, Claire's friend, her analyst, and even the ghost of Madison, who returns to bear witness to what lies beyond witness.

So Claire is left in a position where she cannot avoid dredging the depths: she seeks closure by declaring that 'the girl must be brought up'. As Claire flees for her life from Norman's murderous rage, their truck careers off a bridge into a lake, and makes an uncanny descent to the very place Norman had entombed Madison in her car. Norman makes the last of several attempts to drown Claire, who is rescued by the intervention of the spectral Madison, leaving her husband to die and the young woman to rest at peace in the water. The corpse's face turns to a composite of Madison and Claire, and suggests an affinity between listener and victim. Yet can Claire move on, begin again? The closing scene depicts her standing mutely in a snowy landscape at Madison's grave, transmitting her encounter with the dead woman's otherness. The survivor can speak only of failure at the graveside, just as the father of the burning child can speak only from outside the experience of his son's pain. Trauma is experienced as delay or belatedness; as both films suggest, how can there be a final moment of reckoning, when irretrievable loss can be dealt with? Caruth characterises this 'open' response to trauma as a transformative awakening: 'awakening, in its very inability to see, is thus the 
true reception of an address that, precisely in its crossing from the burning within to the burning without, changes and reforms the addressee around the blindness of the imperative itself' (Caruth, 'Traumatic Awakenings' 101). For one who cannot protect or restore the life of the dead woman, the imperative in What Lies Beneath is to return from the depths of the lake as a living survivor who can bear witness to unbearable fact. Claire cannot 'see' Madison, but can testify to the gap between the living and the dead.

\section{Conclusion}

Caruth argues that the enigmatic core of trauma resides in 'the delay or incompletion in knowing, or even in seeing, an overwhelming occurrence'; there is an 'inherent latency' within the traumatic experience itself (Caruth, Trauma: Explorations in Memory 5, 8). This latency has implications for survivors and witnesses. For the survivor, 'trauma is a repeated suffering of the event, but it is also a continual leaving of its site'. For the witness, '[t]o listen to the crisis of a trauma ... is not only to listen for the event, but to hear in the testimony the survivor's departure from it; the challenge of the therapeutic listener, in other words, is how to listen to departure' (10). Yet what is the nature of that departure in both films? It is not a final reckoning with the past. Grace's initial efforts as a 'survivor' in The Others revolve around the prevention of awakening, of letting light shine in: when illumination eventually arrives, it is less a matter of exposing a terrible secret than of enabling loss to be realised, to be lived with. Similarly, while Claire in What Lies Beneath seems intent on dredging up repressed depths, the emphasis is on coming up for air, surfacing from a state of suspension. Both films issue from the dead, from a paradoxical, impossible call to awaken and survive. If their testimony is a form of witnessing or disclosure, it is not in the service of restitution, retrieval or closure: it 
is about a sense of opening. Their survivors, who are not survivors and yet who live in and with the aftermath, must look to a future that is open to further punctuation, disruption and shock, where past and present collide. In an age of terror and absolutism overshadowed, like Nathaniel in Hoffmann's 'The Sandman', by 'the fear or dread of what may be to come' (Royle viii), we must leave the ruins, bearing pain and loss within us, listening to each other's departures, making the other's crisis our own.

\section{Endnote}

1. Jacques Derrida deploys the term restance on a number of occasions. For the purposes of this essay I am referring to Ian McLeod’s translation note to Derrida's 'Speculations - on Freud', Oxford Literary Review 3: 2 (1978), 78-97, 97.

\section{References}

Amenábar, Alejandro dir. The Others. 2001

Antze, Paul and Michael Lambek eds. Tense Past: Cultural Essays in Trauma and Memory. New York: Routledge, 1996.

Baer, Ulrich. Remnants of Song: Trauma and the Experience of Modernity in Charles Baudelaire and Paul Celan. Stanford, CA: Stanford UP, 2000.

Bass, Ellen, and Laura Davis. The Courage to Heal: A Guide for Women Survivors of Child Sexual Abuse. New York: Harper and Row, 1988.

Brooks, Peter. Troubling Confessions: Speaking Guilt in Law and Literature. Chicago and London: Univ. of Chicago Press, 2000.

Caruth, Cathy. 'Traumatic Awakenings.’ Performativity and Performance. Ed. Andrew Parker and Eve Kosofsky Sedgewick. New York and London: Routledge, 1995. 
---. Unclaimed Experience: Trauma, Narrative, and History. Baltimore and London; Johns Hopkins UP, 1996.

--- ed. Trauma: Explorations in Memory. Baltimore, ML: Johns Hopkins UP, 1995.

Derrida, Jacques. 'Speculations - on Freud.' Trans. Ian McLeod. Oxford Literary Review 3: 2 (1978): 78-97.

Dufresne, Todd. Killing Freud: Twentieth Century Culture and the Death of Psychoanalysis. New York: Continuum, 2003.

Felman, Shoshana, and Dori Laub. Testimony: Crises of Witnessing in Literature, Psychoanalysis and History. New York and London: Routledge, 1992.

Freud, Sigmund. Pelican Freud Library Vol. 4. The Interpretation of Dreams. Ed. Angela Richards. Trans. James Strachey. Harmondsworth: Penguin, 1976.

---. Beyond the Pleasure Principle. Penguin Freud Library Vol. 11. On Metapsychology: the Theory of Psychoanalysis. Ed. Angela Richards. Trans. James Strachey. Harmondsworth: Penguin, 1991: 269-338.

---. 'The Uncanny.’ Penguin Freud Library Vol. 14. Art and Literature. Ed. Albert Dickson. Trans. James Strachey. Harmondsworth: Penguin, 1985: 335-376.

Hirsch, Joshua. After Image: Film, Trauma and the Holocaust. Philadelphia: Temple UP, 2004.

Lacan, Jacques. The Four Fundamental Concepts of Psychoanalysis. Ed. Jacques-Alain Miller. Trans. Alan Sheridan. Norton: New York, 1973.

McNally, Richard J. Remembering Trauma. Cambridge, Mass: Harvard UP, 2003.

Ragland, Ellie. 'Lacan, the Death Drive, and the Dream of the Burning Child.' Death and 
Representation. Ed. Sarah Webster Goodwin and Elisabeth Bronfen. Baltimore, MA. and London: Johns Hopkins University Press, 1993. 80-102.

Rank, Otto. The Double: A Psychoanalytic Study. [1914]. Trans. Harry Tucker Jr. Chapel Hill, NC: University of North Carolina Press, 1971.

Royle, Nicholas. The Uncanny. Manchester: Manchester UP, 2003.

Zemeckis, Robert dir. What Lies Beneath. 2000. 